\title{
Thyroid Gland Follicular Adenoma with Papillary Hyperplasia
}

National Cancer Institute

\section{Source}

National Cancer Institute. Thyroid Gland Follicular Adenoma with Papillary Hyperplasia.

NCl Thesaurus. Code C46111.

A thyroid gland adenoma affecting predominantly children and adolescents. It is composed of branching papillary structures and follicles. 